\title{
The Physiological Change of Two Peony Varieties in dark-induced senescence leaves
}

\author{
Yanwei Cheng ${ }^{1, a, \Delta}$ Mingxin Guo ${ }^{1, \Delta}$ Feng Haiyan ${ }^{1, \Delta}$ Li Wenqian ${ }^{1, \Delta}$ Huanling \\ Zhang $^{2}$ Kai Gao ${ }^{3}$ Yanzhao Zhang ${ }^{1}$ Han Jianming ${ }^{1, b^{*}}$ \\ ${ }^{1}$ Life science College, Luoyang Normal University, Luoyang 471022, China \\ ${ }^{2}$ Peony Institute of Luoyang, , Luoyang 471022, China \\ ${ }^{3}$ Luoyang Academy of Agriculture and Forestry Sciences, Luoyang471023, China \\ aemail: cywztg@qq.com, bemail: 792531425@qq.com \\ * The Corresponding author: Han Jianming \\ $\Delta$ These authors contributed equally to this study
}

Keywords: Peony;; SOD; Protein content; Chlorophyll content

Abstract: Leaf senescence regulatory mechanism was studied for many years for revealing the physiological and biochemical mechanism. In this experiment, two peony varieties, Juanyehong and Roufurong were studied for uncover the physiological change during dark-induced senescence leaves, including protein content, superoxide dismutase (SOD), chlorophyll content. In flowering period, the deepest color leaves which is collateral to the lower side of the plants, were placed moist gauze in a Petri dish, wrapped in newspaper, and dark induced at $25{ }^{\circ} \mathrm{C}$ incubator. SOD activity, chlorophyll content ,protein content were tested during dark-induced senescence leaves . The results showed that SOD activity, chlorophyll content and protein content were significantly reduced with the leaf senescence.

\section{Introduction}

In recent years, physiological mechanism of leaf senescence was studied in many plants. The contents of chlorophyll, protein and photosynthetic rate of the leaves were the main items for the determination.. Since the end of the 1960s, Fridovich et al put forward biological free radical damage theory.The accumulation of reactive oxygen species, free radicals of the impact of leaf senescence has made great progress [1].

Superoxide dismutase (SOD) is a important superoxide anion free radical scavenger, which can maintain the free radicals in the body and clear the dynamic balance of a metal enzyme (with enzymes), so as to avoid adverse reactions caused when a superoxide anion free radical concentration is too high in the aging [2]. SOD has special physiological activity, is the first substance of the organism to remove the free radicals. The level of SOD in living organisms means the visual index of aging and death..It can resist and block the damage caused by oxygen free radicals to the cells, and repair damaged cells in time, and cause the damage to the cells caused by free radicals. The SOD status in human life is increasingly important. Superoxide dismutase (SOD) used in clinical medicine can treat a variety of diseases, rheumatoid arthritis, myocardial infarction, in radiation resistant, anti-aging, antitumor and other aspects also have an active role,which are widely used in cosmetics and food additives[3]. This experiment the change of SOD activity were measured by nitroblue tetrazolium method during the dark induced senescence of peony leaves. It has a important significance for using the peony resources and promoting the peony industry development. 


\section{Materials and Methods}

Materials and equipment

Materials

Juanyehong and Roufurong of peony fresh leaves, from the Institute of Luoyang Peony.

The dark induced senescence of peony leaves in vitro

The peonies were grown to flowering stage, whichever is the lowest collateral that is the darkest side of the blade, which was covered with wet gauze placed in a petri dish, dark-handle wrapped in newspaper, in the dark at $25^{\circ} \mathrm{C}$ incubator and took sample for 1 time every $24 \mathrm{hr}$, samples were placed in a refrigerator at $-20{ }^{\circ} \mathrm{C}$ until use. Each sample were measured SOD activity, protein content, chlorophyll content.

Reagents

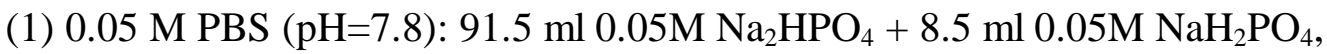

(2) $130 \mathrm{mM}$ Met solution: weigh $1.9399 \mathrm{~g}$ Met with PBS to $100 \mathrm{ml}$,

(3) $750 \mu \mathrm{M}$ NBT solution: weigh $0.06133 \mathrm{~g}$ NBT with PBS volume to $100 \mathrm{ml}$, stored in the dark,

(4) $100 \mu \mathrm{M}$ EDTA-Na $\mathrm{Na}_{2}$ solution: weight $0.03721 \mathrm{~g}$ EDTA- $\mathrm{Na}^{2}$ with PBS volume to $1000 \mathrm{ml}$,

(5) $20 \mu \mathrm{M}$ Riboflavin solution: weigh $0.0753 \mathrm{~g}$ riboflavin with distilled water volume to $1000 \mathrm{ml}$, stored in the dark.

The main instruments

UV spectrophotometer, high-speed desktop centrifuge, electronic scales, mortar, pipette, light incubator, test tube.

Test Method

Extraction of crude enzyme solution process refer to Anzhong Pan etc[4]

Sampled the Peony leaves and removed veins, washed with tap water, distilled water rinse to dry, weight $0.52 \mathrm{~g}$ in pre-cooling mortar, add $1 \mathrm{ml}$ per-cooling PBS to grind slurry, add a buffer to a final volume of $4 \mathrm{ml}$. Take $4 \mathrm{ml}$ in 10,000 r/min centrifuge $20 \mathrm{~min}$, the supernatant is SOD crude extract. Determination of SOD activity using NBT method.

Determination of SOD activity refer to Zheng Zhang etc [5] nitroblue tetrazolium (NBT) method. Protein content determination

$0.5 \mathrm{~g}$ leaves and $3 \mathrm{ml}$ Tris- $\mathrm{HCl}$ buffer $(\mathrm{pH} 7.5,50 \mathrm{mM}$, containing EDTA1 $\mathrm{mM}$ and mercaptoethanol $15 \mathrm{mM}, 1 \% \mathrm{PVP}$ ) and a small amount of quartz sand grinding in a mortar pre cooling, and then $30 \mathrm{~min}$ at $10,000 \mathrm{r} / \mathrm{min}, 4^{\circ} \mathrm{C}$ centrifugal and supernatant crude enzyme solution. Referring to Bradford, bovine serum albumin as the standard protein.

Determination of chlorophyll content

Weight $0.1 \mathrm{~g}$ leaves, wash, drain water, cut into $1-2 \mathrm{~mm}$ wide, add $10 \mathrm{ml}$ of extraction liquid (acetone, ethanol volume mixing) sealing, placed in $60^{\circ} \mathrm{C}$ water bath in rapid extraction 30 min to materials, taking supernatant fluid at $663 \mathrm{~nm}$ and $645 \mathrm{~nm}$ wavelength measured OD values.

Total chlorophyll content $(\mathrm{mg} / \mathrm{g})=(8.04 \mathrm{~A} 663+20.19 \mathrm{~A} 645)-\mathrm{V} /(103-\mathrm{W}), \mathrm{V}$ volume $(\mathrm{ml})$, and $\mathrm{W}(\mathrm{g})$ materials weight.

\section{Results and Analysis}

Activity of SOD in the dark induced leaf senescence

In dark induced senescence, SOD activity in leaves of two species of peony Juanyehong and Roufurong had the trend to reduce. In the whole experiment process Roufurong SOD activity decreased to a lesser extent, and no obvious change, Juanyehong SOD activity in dark induced before $72 \mathrm{hr}$ decreased to a lesser extent, between the 72h-96h change is obvious (Fig. 1). 


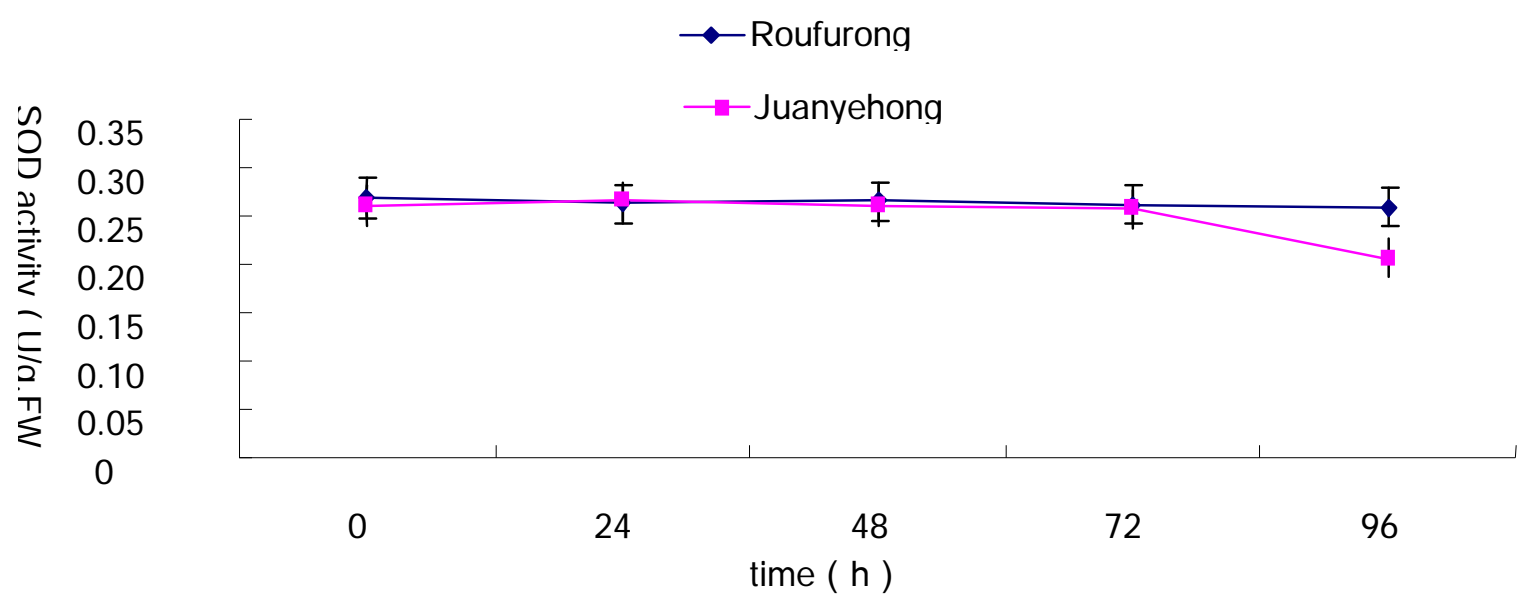

Fig. 1 Activity changes of SOD during dark induced aging process

Changes of protein contents during dark induced senescence of two peony leaves:

The protein content of the two peony leaves was decreased, but the trend of decrease was slightly different from the whole process of plant dark induced senescence.. Before the dark induced $24 \mathrm{hr}$, the Roufurong decreased slowly, but after $24 \mathrm{hr}$ until $96 \mathrm{hr}$, the decrease rate of Roufurong was fast and stable. The content of the protein in the leaves of the Juanyehong before dark induced $72 \mathrm{hr}$ was stable, but the protein content decreased rapidly between $72 \mathrm{hr}-96 \mathrm{hr}$ (Fig.2).

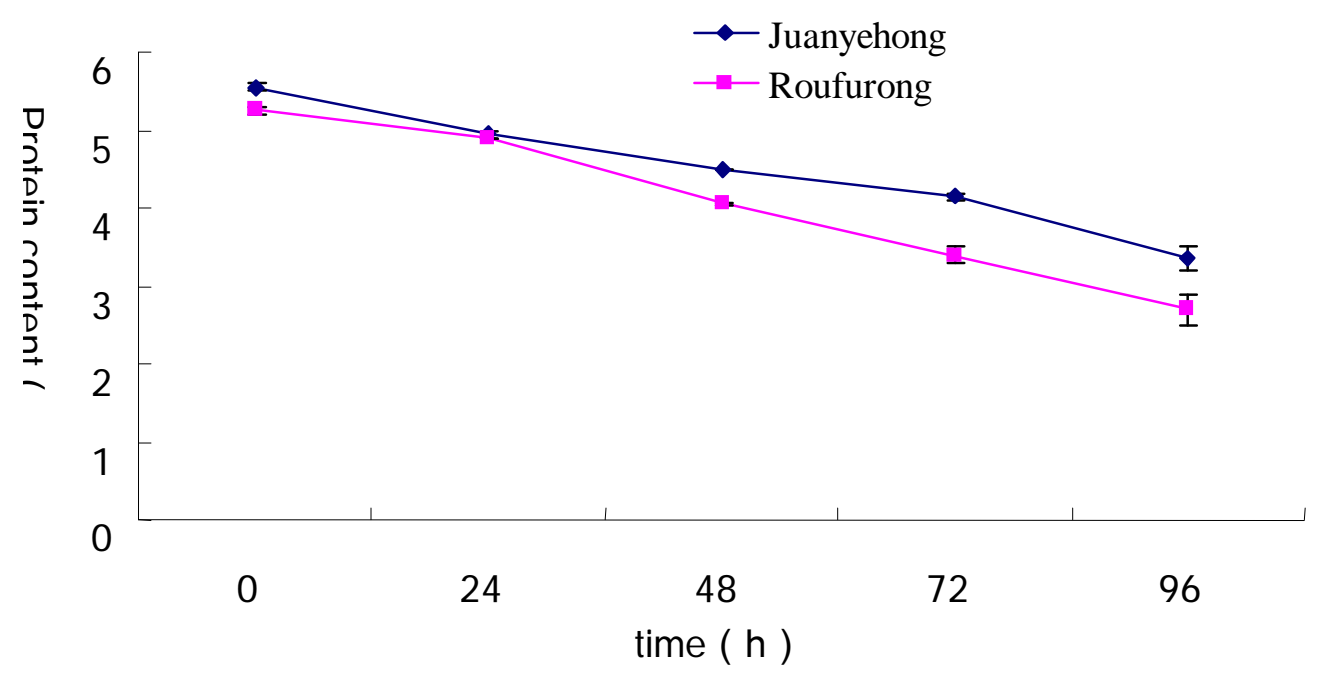

Fig. 2 Changes of protein contents during dark induced senescence

The change of the activity of chlorophyll in two leaves during the dark induced senescence

During the whole experiment, the chlorophyll content of two kinds of peony leaves were decreased, and the downward trend is similar. Before the dark induced to $72 \mathrm{hr}$, the chlorophyll content of the two decline rate is slow and stable, and Roufurong are declined rapidly d uring $72 \mathrm{hr}-96 \mathrm{hr}$ (Fig.3). 


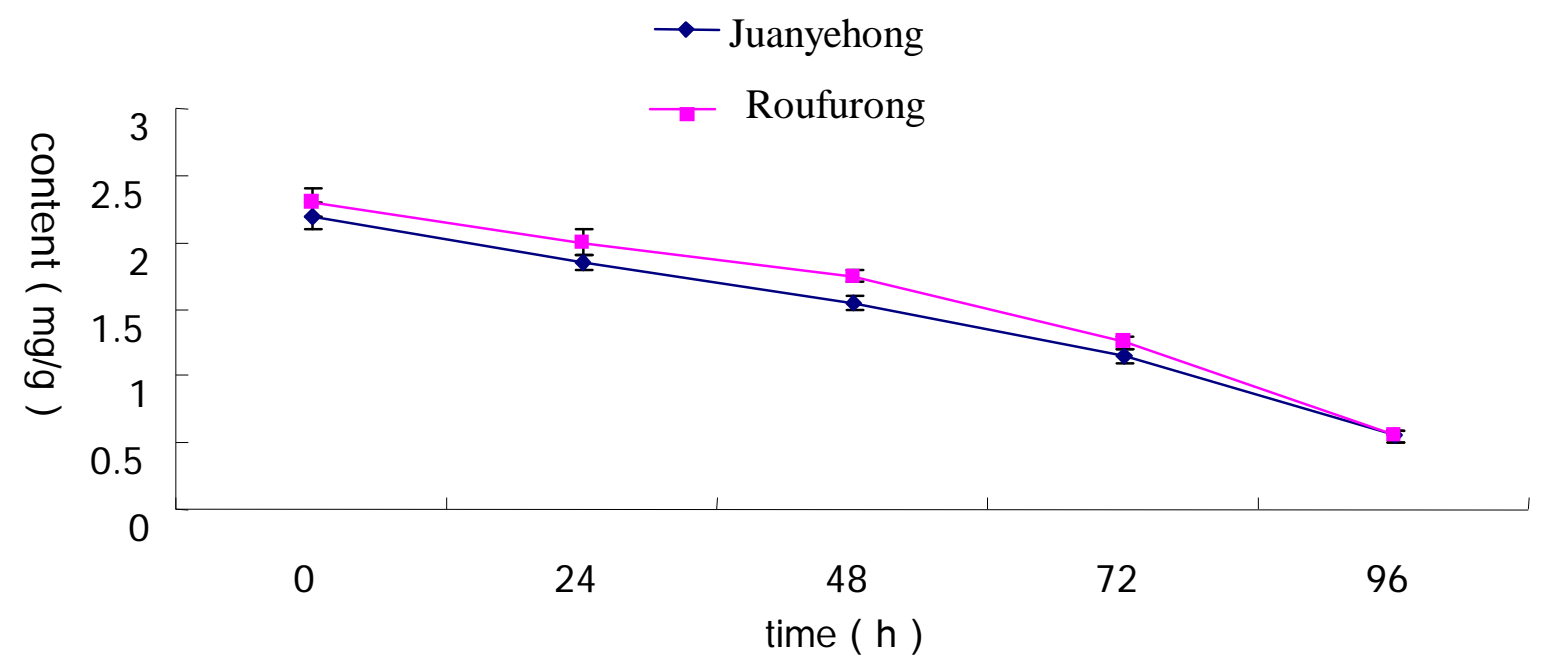

Fig. 3 The activity of chlorophyll during dark induced senescence

\section{Discussion}

Through this experiment, we investigate the dark induced senescence changes in Juan yehong and Roufurong two peony leaves SOD activity and the content of chlorophyll, soluble protein content. Many experiments indicated that the leaf senescence were positively related to active oxygen metabolism [6], and the process of leaf senescence was the accumulation of reactive oxygen and free radical metabolism in vivo. Plants in the normal metabolic processes can be through a variety of ways to produce $\mathrm{H}_{2} \mathrm{O}_{2}, \mathrm{ROOH}$ and $\mathrm{CO}_{2}$ are collectively referred to as reactive oxygen species. They can lead to cell damage, lead to enzyme inactivation, destroy DNA structure, DNA replication damage, interfere with protein synthesis, started the membrane lipid oxidation reaction, maintaining cellular compartmentation of membrane damage or collapse, Simultaneous intracellular removal of these reactive oxygen species [7].

The antioxidant effect of plants is an important aspect of adaptive regulation of plant itself, and SOD is an important protective enzyme in the active oxygen scavenging system of plants[8].The higher the degree of senescence, the faster the activity of SOD in the leaves decreased, and the toxic effect of reactive oxygen species in the leaves of the leaves. During the leaf senescence, the accumulation of MAD caused by the enhancement of lipid peroxidation caused the accumulation of the membrane, which affected the metabolism of the membrane, and accelerated the leaf senescence. The protein in the mature tissues is in a relatively constant turnover, so the stability of the cell organization is maintained by a synthesis and decomposition of the balance system [9] But the balance of the plant leaves is broken and the degradation of protein is the degradation of protein.

Zai et al[10] observed that when plants were aged, the protein was hydrolyzed to the RuBP of the plant photosynthesis and it was a major leaf protein component. Along with the beginning and the process of leaf senescence, the activity of ammonia - peptide and enzyme in the leaves of the leaves increased significantly, which resulted in the enhancement of protein hydrolysis and the decrease of soluble protein content. Ding et al [11] with cucumber cotyledons do materials research reports, along with the senescence of cucumber cotyledons, cotyledons decreased the content of soluble protein, cotyledon of several main free amino acid accumulation increased significantly, especially with glutamic acid and arginine is most obvious. Because the leaf senescence process of protein is gradually stable down, so the degradability of protein are regarded as the criterion of senescence degree [12] Many studies have indicated that there is a negative correlation between chlorophyll content and senescence. Leshem research suggests that chlorophyll gradually disappearing is the most obvious manifestation of leaf senescence, and accompanied by a yellowing and leaf eventually fall off., Nie et alshowed that the senescence of the leaves increased while the chlorophyll content of the leaves of the rice leaves decreased as the days increased of the detached leaves [13]. From the changes of 
chloroplast ultrastructure during the senescence, the chloroplast gradually disintegrated with age. Therefore it has been the decomposition of the chlorophyll that is the signs of the aging of the real primary process.

\section{Acknowledgement}

This work was supported by the NSFC -Henan province joint foundation (U1204307), the NSFC(31400602), and the Science and Technology Key Projects of Henan Province (142102110173 , 152102210334) , the cultivation fundation supported by Luoyang Normal University(2013-PYJJ-001),

\section{References}

[1] J. M. McCORD, FRIDOVICHI.SOD:an enzymic function for erythrocuprein (hemocuprein). J.Biol.Chem. 224(1969)6049-6055.

[2] Hong Wang, Ningfeng Wang. Determination of highland barley in Qinghai seedlings SOD Guangdong chemical. 37(2010)107-108. In Chinese.

[3] Changying Dong, Qiao Zhang. Determination of the activity of superoxide dismutase in three species of aloe. North Horticulture. 5(2009)97-99. In Chinese.

[4] Anzhong Pan, Shulian Xie, Xuemei Qin. Seeds of Bupleurum chinense in different years SOD, POD activity and germination rate determination. Tianjin Hospital of traditional Chinese medicine. 25(2008)3. In Chinese.

[5] Zheng Zhang, Zhuanhua Wang, Rufa Lin . The effect of $\mathrm{Cu}, \mathrm{Pb}$ and $\mathrm{C}$ on the antioxidant enzymes activity of buckwheat seeds. Chinese Journal of Biochemistry and molecular biology. 15 (1999)850-853. In Chinese.

[6] Haitao Wang, Yangliang Yang, Huibi Xu. Signal molecules of reactive oxygen species. life of chemical . 21 (2001)39-41. In Chinese.

[7] W.M.Kaiser. The effect of hydrogen peroxidide on $\mathrm{CO}_{2}$ fixation of isolated intact chloroplasts. Biochem. Biphys.Acta. 400(1976)476-482.

[8] Ning Liu, Yubao Gao, Caixia Jia et al. Osmotic stress spend leaves of Lolium perenne peroxidase activity and proline content and plasma membrane permeability changes. Plant Physiology Communications school. 36 (2000):11-14. In Chinese.

[9] HUFFAKER E C, PETERSON L W. Protein turnover in plants and possible means of its regulation. Ann.Rev.Plant Physiol.25(1974)363.

[10] Jinping Dai, Zhengyan Shen, Lingcheng Jian. Effect of low temperature exercise on the activity of several enzymes of cucumber seedlings. Plant. 33(1991) 627-632. In Chinese.

[11] Wenming Ding, Yuju Zhao. Effects of brassinosteroids lactone on Cucumber Cotyledon peroxidase activity and soluble protein content of the. Journal of Plant Physiology. (1995)259-264. In Chinese.

[12] Kaoshan Chen, Chenglie Zhang, Houguo Liang. During bean leaf senescence chloroplast membrane lipids and fatty acid composition changes. Journal of Plant Physiology. 17(1991)139-144. In Chinese.

[13] Xianzhou Nie, Daohong Liu, Zhusheng Xu. Lipid peroxidation in rice flag leaf and leaf $\mathrm{Ni}^{2+}, \mathrm{Ag}^{+}$ relationship. Plant physiology communication.2(1989)32-34. In Chinese. 